\title{
An outbreak of skin sepsis in abattoir workers caused by an 'unusual' strain of Streptococcus pyogenes
}

\author{
G. PHILLIPS, A. EFSTRATIOU*, A. TANNA*, B. BEALL†, J. FERGUSON $\ddagger$ and M. ROWORTH§
}

Department of Medical Microbiology, Ninewells Hospital and Medical School, Dundee DD1 9SY, *PHLS Respiratory and Systemic Infection Laboratory, Central Public Health Laboratory, London NW9 5HT, †Division of Bacterial and Mycotic Diseases, Centers for Disease Control and Prevention, Atlanta, GA 30333, USA, $\$$ Department of Dermatology, Ninewells Hospital, Dundee DD1 9SY and §Public Health Medicine, Tayside Health Board, King's Cross Hospital, Dundee DD3 8EA

\begin{abstract}
An outbreak of indolent skin infections due to an 'unusual' serological type of Streptococcus pyogenes that lasted for 3 months and affected eight workers in an abattoir is described. The group A streptococcal (GAS) isolates were serotyped as Mtype 59; however, they possessed a T-protein pattern (T5/27/44) that is not commonly associated with M-type 59. Further genotypic characterisation studies revealed that all eight isolates were indistinguishable by pulsed-field gel electrophoresis (PFGE) and possessed the emm gene encoding for the M-type 59. Once identified, and after a combination of penicillin treatment, exclusion of workers with lesions and reinforcement of standard hygiene precautions, no further cases developed. Although common in the 1970s and 1980s, streptococcal infections in this situation are now reported infrequently. This report serves to highlight the issues surrounding working practices in abattoirs.
\end{abstract}

\section{Introduction}

Epidemic and sporadic cases of Streptococcus pyogenes skin infection have been described in abattoirs in the UK and USA since the 1970s [1,2], although such descriptions are now much less frequent. Most of these outbreaks were caused by group A streptococci (GAS) belonging to particular M-types or new types designated at that time as provisional types (PT), e.g., PT2681 (M-type 80), PT2015 (M-type 79), PT943 (Mtype 76) [3]. This report describes such an outbreak caused by an unusual strain of $S$. pyogenes. The eight isolates from the incident of skin sepsis amongst abattoir workers described here were examined by conventional serotyping and were further characterised by genotypic methods, i.e., pulsed-field gel electrophoresis (PFGE), the presence of streptococcal pyrogenic exotoxin genes (spe $A, B, C$ ) and emm gene sequencing. The conventional typing scheme for GAS is traditionally based upon the association of T-protein antigens, the opacity factor and M-protein. The emm gene sequences of most GAS isolates (there are $>100$ different sequence types) usually correlate with the classical M-protein type for that strain [4-7].

Received 22 June 1999; accepted 1 Oct. 1999.

Corresponding author: Dr G. Phillips.

\section{Materials and methods}

Description of outbreak

Eight male workers from a local abattoir (four meat processors, three slaughtermen and one driver) were examined at Dermatology Outpatients, Ninewells Hospital after referral by the abattoir medical staff. All presented with poorly healing lesions on exposed skin sites - mainly the fingers, hands or arms. Six workers had a history of preceding trauma to the skin from either bone splinter injuries or cuts. All reported nodule formation within the skin followed by breakdown with persistent exudate and failure to heal. Three workers reported having had the lesions persistently for the previous 4-6 weeks. Wound swabs from 10 workers with a history of skin lesions and one secondary contact with a sore hand were submitted to the laboratory. Throat swabs were taken from nine workers and the secondary contact.

\section{Primary microbiological cultures}

Wound swabs were examined by culture on to horse blood agar incubated aerobically and anaerobically at $37^{\circ} \mathrm{C}$ overnight. Throat swabs were examined by culture on to horse blood agar and incubated anaerobically at $37^{\circ} \mathrm{C}$ overnight. Any $\beta$-haemolytic 
streptococci were Lancefield grouped by means of a streptococcal grouping kit (Oxoid).

\section{Serological typing}

Isolates of GAS were sent to the PHLS Streptococcus Reference Unit (Public Health Laboratory Service, Streptococcus and Diphtheria Reference Unit, SDRU, Colindale London) for confirmation of identity. Isolates were serotyped according to conventional methods [8].

\section{Genotypic characterisation}

The PCR method and PFGE profiles were undertaken as described by Stanley et al. [5]. Emm gene 5' sequencing and HincII/Hae III restriction profiling of emm gene-specific PCR fragments were performed as described previously $[7,9]$. The PCR primers used for detection of the exotoxin genes were derived from documented nucleotide sequences [10-12] and PCR assays [13]. The $5^{\prime} \mathrm{emm}$ sequence was analysed with Genetics Computer Group version 9 software as described previously [9].

\section{Results}

\section{Microbiological cultures}

Pure growths of Lancefield group A $\beta$-haemolytic streptococci were isolated from the skin swabs of seven workers: one worker was positive for GAS in both wound and throat swabs and another was positive in the throat swab only. Wound and throat swabs from the secondary contact were negative on culture.

\section{Serological typing}

Isolates from each of the eight workers from whom GAS were isolated were confirmed as $S$. pyogenes by the Streptococcus Reference Unit. All exhibited the same T-type pattern of $\mathrm{T} 5 / 27 / 44$; they were opacity- factor (OF) positive and precipitated with M-type 59 antiserum. Anti-opacity factor tests correlated with the M-type (Table 1).

\section{Genotypic characterisation}

Strain SA97/195 5' emm sequence was identical to the CDC reference strain SS913 and the reference M-type 59 strain NCTC 10877 over at least their first 450 bases. Furthermore, the emm amplicon generated from SA97/195 gave a HincII/Hae III cleavage profile identical to 17 independent emm59 isolates encountered previously [7]. A PCR amplicon from the speB gene was generated from all isolates. All outbreak Mtype 59 strains were indistinguishable by PFGE and were distinguishable from the sporadic non-related isolates that were received by the laboratory in Dundee during that period (Fig. 1). The size of the PFGE products ranged from $970 \mathrm{~kb}$ to $48.5 \mathrm{~kb}$.

\section{Management of the outbreak}

All infected workers were treated with penicillin V $250 \mathrm{mg}$ qds for 10 days and concomitant iodine powder spray applied twice daily to the lesions. Clinical resolution was achieved in six patients by the end of the treatment course. The remaining two workers responded to a further 2 weeks of therapy. The abattoir had a total of 31 employees. A further 26 employees in the adjacent meat cutting and processing plant shared the same hand-washing and shower/toilet facilities. In a case finding exercise at the plant, the hands of a further 36 employees were inspected for skin lesions and the patients were asked about the presence of superficial lesions elsewhere on the body or in members of their immediate family. Given the finding of $S$. pyogenes in the respiratory tracts of two of the initial eight workers, throat swabs were taken from the remaining employees. No further skin lesions were detected or reported and no further isolations of $S$. pyogenes were made during this exercise. There was no

Table 1. Phenotypic and genotypic characterisation of GAS isolates from the abattoir outbreak and other non-related infections

\begin{tabular}{llllll}
\hline Lane no. $^{*}$ & Strain reference no. & PFGE type & M-type & T-type & spe genes \\
\hline 1 & SA97/178 & P1 & M59 & $5 / 27 / 44$ & B \\
2 & SA97/179 & P1 & M59 & $5 / 27 / 44$ & B \\
3 & SA97/195 & P1 & M59 & $5 / 27 / 44$ & B \\
4 & SA97/196 & P1 & M59 & $5 / 27 / 44$ & B \\
5 & NCTC 10877 & P2 & M59 & $8 / 25 /$ IMP19 & $\ldots$ \\
6 & SA97/197 & P1 & M59 & $5 / 27 / 44$ & B \\
7 & SA97/198 & P1 & M59 & $5 / 27 / 44$ & B \\
8 & SA97/199 & P1 & M59 & $5 / 27 / 44$ & B \\
9 & SA97/200 & P3 & M12 & 12 & B \\
10 & NCTC 10877 & P2 & M59 & $8 / 25 /$ IMP19 & $\ldots$ \\
11 & SA97/201 & P3 & 12 & 12 & B \\
12 & SA97/202 & - & 4 & 4 & BC \\
13 & SA97/257 & P4 & 11 & 11 & BC \\
14 & SA97/258 & P1 & 59 & $5 / 27 / 44$ & B \\
15 & SA97/298 & P3 & 12 & 12 & B \\
\hline
\end{tabular}

* Corresponding to PFGE profiles in Fig. 1.

${ }^{\dagger}$ Non-related sporadic isolates from skin and throat referred to the laboratory in Dundee during the period of the outbreak. 


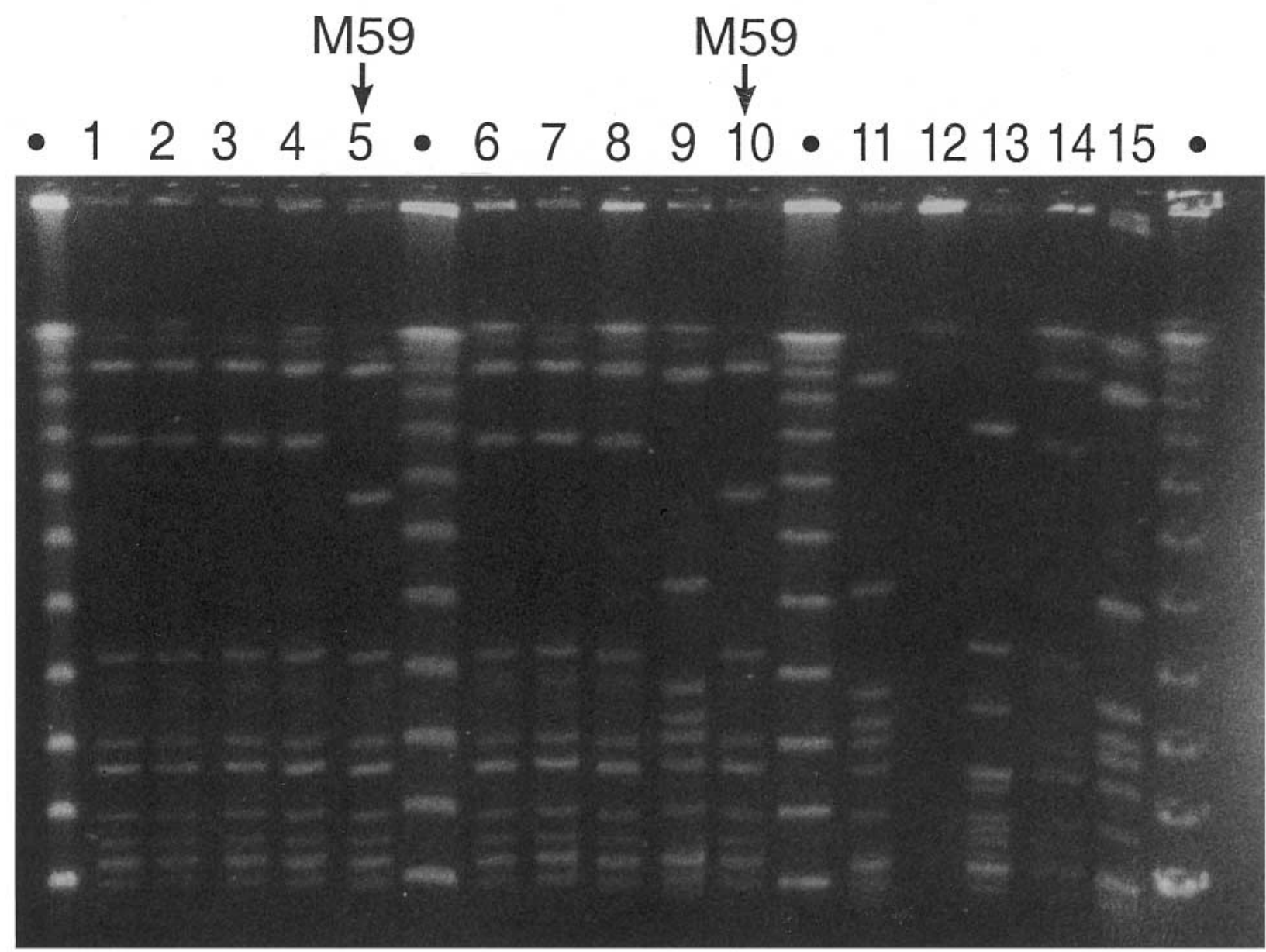

Fig. 1. Sma I macro-restriction profiles resolved by PFGE. Mol. wt markers (sonicates of phage 7), lanes 1-4, 6-8 and 14, 'outbreak' group A streptococcal isolates; 9, 11, 12, 13, 15, non-related sporadic isolates; 5 and 10, M59 reference type strain NCTC 10877; • mol. wt markers in kb (top left) 970, 921.5, 873, 824.5, 776, 727.5, 679, 630.5, 582, 533.5, 48.5 (bottom left).

evidence of further secondary spread in the families of employees.

An Outbreak Control Team was convened with membership from the abattoir and meat processing plant management, Environmental Health Department, Meat Hygiene Service, Microbiology, Dermatology and the Public Health Department. Routine practices regarding hygiene measures in the abattoir were discussed and the provision of facilities for handwashing and -drying, showers, toilets and laundry was reviewed. Anecdotal information had been received about the lack of adequate hand-drying facilities, but at the time of the meeting, the Meat Hygiene Service Officers reported that these were satisfactory.

Additional cleaning routines for the abattoir and meat processing plant were agreed. Advice regarding hygiene measures for those working in areas where food is prepared was issued to managers at the abattoir and meat processing plants and relayed to all employees [14]. Explanatory letters were sent to all infected workers giving general information about transmission and treatment of the infection and action to be taken if any family members showed symptoms. All local
Family Practitioners were sent a letter giving details of the outbreak at the abattoir and advice on the management of further cases amongst contacts. No further cases were reported after the initial outbreak.

\section{Discussion}

S. pyogenes infection amongst meat handlers is well recognised, with sizeable outbreaks being reported in the $1970 \mathrm{~s}$ and $1980 \mathrm{~s}[15,16]$. Interim advice on the prevention of streptococcal infection in meat handlers was published by the Public Health Laboratory Service Working Group on Streptococcal Infection in Meat Handlers in 1983 [17] which emphasised basic hygiene measures and there are now few reports of the problem. The last incident of GAS skin sepsis amongst meat workers that occurred in the UK was in 1993 in the South West of England. Thirteen cases were documented with the predominance of serotype M76 (personal communication, PHLS SDRU). Spread is usually via person-to-person contact and facilitated by the frequency of splinters and cuts on the hands [16]. An autumnal predominance of the infection has been noted and strike rates can be high [17]. This outbreak was 
well established and possibly even declining before microbiological investigations were instigated. Following identification and treatment of the infected cases and general cleaning of the premises, no further problems were reported. The source of the outbreak was never identified, but some of the workers did volunteer that they had occasionally shared handdrying materials and it is possible that these acted as vehicles of transmission, as well as more direct contacts between employees. Because meat is not regarded as a primary reservoir of $S$. pyogenes the risk to the public from secondary contamination of a product which would be cooked prior to consumption was deemed to be negligible. No environmental swabbing was performed, but it is recognised that the organism may survive on working surfaces and equipment [17].

The GAS isolates from this outbreak were serotyped as T5/27/44, M59 which was an unusual combination, as the classic M59 strain is usually T8/25/IMP19. The serotype M59 had not been isolated previously from outbreaks of skin sepsis amongst meat workers. It is, overall, an uncommon serotype within the UK and is classically associated with skin infections in tropical areas. The serotype was first documented in the late 1960s in a case of glomerulonephritis following skin sepsis [18]. We and others have found that emm59 strains often carry T8/25/IMP19 or T11/12 and are opacity factor positive [14]. The association of the T5/27/44 pattern with a T12, OF positive, anti-OF 59 positive, emm59 strain suggested that this outbreak strain phenotype may have resulted from an intraspecies recombination event with a $\mathrm{T} / 5 / 27 / 44$ strain at a locus distinct from the T12 antigen determinant. This is consistent with the observation that many of the $T$ antigen genes are not homologous to one another and are unlikely to lie at the same chromosomal loci [19].

'Meat association' of particular serotypes of GAS may be a character distinct from the ability to cause pyoderma and minor skin sepsis. Isolates from meat handlers belong to a variety of serotypes, often distinct from those causing infections in the community at large [2]. The most common serotypes that have been associated with abattoir workers during the last 15 years are M49, M80, M81 and PT4854; however, 30\% of strains are non-typable. It is not known whether the infrequency of type-specific antibody to the supposed infecting strains can be attributed to the failure of wound infections to elicit the antibody response, as appears to be the case with streptococcal pyoderma [3].

\section{References}

1. Center for Disease Control. Group-A, -B hemolytic Streptococcus skin infections in a meat-packing plant - Oregon. MMWR Morb Mortal Wkly Rep 1986; 35: 629-630.

2. Fraser CAM, Ball LC, Morris CA, Noah ND. Serological characterization of group-A streptococci associated with skin sepsis in meat handlers. J Hyg 1977; 78: 283-296.

3. Tsai TF, Watson WN, Hayes PS, Facklam RR, Fraser DW. Mode of spread of group-A streptococci in an abbatoir outbreak of wound sepsis. In: Parker MT (ed) Pathogenic streptococci. Chertsey, Reedbooks. 1979: 118-119.

4. Johnson DR, Kaplan EL, Sramek J et al. In: Laboratory diagnosis of Group A streptococcal infections. Geneva, World Health Organization. 1996.

5. Stanley J, Desai M, Xerry J, Tanna A, Efstratiou A, George R. High-resolution genotyping elucidates the epidemiology of group A streptococcus outbreaks. J Infect Dis 1996; 174: 500506.

6. Beall B, Facklam R, Thompson T. Sequencing emm-specific PCR products for routine and accurate typing of group A streptococci. J Clin Microbiol 1996; 34: 953-958.

7. Beall B, Facklam RR, Elliot JA et al. Streptococcal emm types associated with T-agglutination types and the use of conserved emm gene restriction fragment patterns for subtyping group A streptococci. J Med Microbiol 1998; 47: 893-898.

8. Johnson DR, Kaplan EL. A review of the correlation of Tagglutination patterns and M-protein typing and opacity factor production in the identification of group A streptococci. $J$ Med Microbiol 1993; 38: 311-315.

9. Beall B, Facklam R, Hoenes T, Schwartz B. Survey of emm gene sequences and T-antigen types from systemic Streptococcus pyogenes infection isolates collected in San Francisco, California; Atlanta, Georgia; and Connecticut in 1994 and 1995. J Clin Microbiol 1997; 35: 1231-1235.

10. Weeks CR, Ferretti JJ. Nucleotide sequence of the type A streptococcal exotoxin (erythrogenic toxin) gene from Streptococcus pyogenes bacteriophage T12. Infect Immun 1986; 52: $144-150$.

11. Hauser AR, Schlievert PM. Nucleotide sequence of the streptococcal pyrogenic exotoxin type B and relationship between the toxin and the streptococcal proteinase precursor. $J$ Bacteriol 1990; 172: 4536-4542.

12. Goshorn SC, Bohach GA, Schlievert PM. Cloning and characterization of the gene, speC, for pyrogenic exotoxin type C from Streptococcus pyogenes. Mol Gen Genet 1988; 212: $66-70$.

13. Musser JM, Kapur V, Szeto J, Pan X, Swanson DS, Martin DR. Genetic diversity and relationships among Streptococcus pyogenes strains expressing serotype M1 protein: recent intercontinental spread of a subclone causing episodes of invasive disease. Infect Immum 1995; 63: 994-1003.

14. Food handlers: fitness to work. Guidelines for food business managers, Enforcement Officers and health professionals. Wetherby, Department of Health. 1995: 6-12.

15. Barnham M, Kerby J. A profile of skin sepsis in meat handlers. J Infect 1984; 9: 43-50.

16. Barnham M, Kerby J. Skin sepsis in meat handlers: observations on the causes of injury with special reference to bone. J Hyg 1981; 87: 465-476.

17. Morris CA, Fell HWK, Boissard JM et al. The epidemiology and control of streptococcal sepsis in meat handlers. Public Health Laboratory Service Working Group. Environ Health 1992; 9: 256-258.

18. Dillon HC. Pyoderma and nephritis. Annu Rev Med 1967; 18: 207-218.

19. Schneewind O, Jones KF, Fischetti VA. Sequence and structural characteristics of the trypsin-resistant T6 surface protein of group A streptococci. J Bacteriol 1990; 172: 3310-3317. 